\title{
Formation and Stability of Solid Lipid Nanoparticles Fabricated using Phase Inversion Temperature Method
}

\section{SONGRAN GAO AND DAVID JULIAN MCCLEMENTS*}

Biopolymers and Colloids Laboratory, Department of Food Science, University of

Massachusetts Amherst, Amherst, MA 01003

\section{Submission Journal: Colloids and Surfaces A}

Submission Date: January 5, 2016

Revision Date: February 7, 2016

${ }^{*}$ To whom correspondence should be addressed. Tel: (413) 545-1019. Fax: (413) 545-1262. E-mail:

mcclements@foodsci.umass.edu. 


\section{Abstract}

22 Solid lipid nanoparticles (SLNs) are being investigated for their ability to encapsulate and protect

23 lipophilic bioactive compounds in foods, supplements, and pharmaceuticals. In this study, the phase

24 inversion temperature (PIT) method was used to fabricate SLNs using a model surfactant (Brij 30,

$25 \mathrm{C}_{12} \mathrm{E}_{4}$ )/ oil (octadecane) / water system. Surfactant/oil/water (SOW) mixtures were maintained at a

26 temperature above the PIT, and then rapidly cooled to a temperature below the lipid nanoparticle

27 crystallization point. The PIT $\left(\approx 40^{\circ} \mathrm{C}\right)$ was determined by monitoring the turbidity versus temperature

28 profile of the SOW system during heating. The lipid nanoparticle crystallization point, melting point,

29 and physical state were determined using differential scanning calorimetry (DSC). The stability of the

30 lipid nanoparticles after fabrication depended on the storage temperature relative to the PIT and

31 melting/crystallization points. At temperatures appreciably below their melting point $\left(\approx 26^{\circ} \mathrm{C}\right)$, the lipid

32 nanoparticles were completely solid and stable to aggregation. At temperatures around their melting

33 point, the lipid nanoparticles were partially crystalline, which led to partial coalescence and gelation.

34 At temperatures appreciably above their melting point but below their PIT, the lipid nanoparticles were

35 completely liquid and prone to coalescence and phase separation. These results have important

36 implications for optimizing the fabrication and storage conditions required to produce stable

37 nanoemulsions suitable for utilization in commercial products using low-energy methods.

Keywords: Solid lipid nanoparticles; Phase inversion temperature; Nanoemulsions;

40 Crystallization; Low-energy; Stability 
Bioactive lipophilic ingredients, such as oil-soluble vitamins, nutraceuticals, nutrients, antioxidants, antimicrobials, flavors, and pigments, are increasingly being utilized to fortify foods and beverages because of their potential to improve product safety, shelf-life, quality, and nutritional aspects $[1,2]$. Nevertheless, the incorporation of these bioactive ingredients into foods is often challenging because of their low water-solubility, food matrix incompatibility, poor chemical stability, undesirable flavor profile, and/or low bioavailability [3, 4]. Solid lipid nanoparticles (SLNs) are a type of colloidal delivery system that has been widely studied for its potential to encapsulate, protect, and release lipophilic active ingredients in the pharmaceutical, supplement, and food industries [5-11]. SLNs consist of a suspension of crystalline lipid nanoparticles dispersed within an aqueous medium, with each nanoparticle being stabilized against aggregation by an emulsifier coating. SLNs have been claimed to have advantages over liquid lipid nanoparticles (LLNs) for certain applications [12-14]. The crystallization of the lipid phase may retard molecular diffusion within the nanoparticle interior, thereby improving the retention and chemical stability of encapsulated bioactive ingredients [5]. SLNs therefore have considerable potential for utilization within the food industry to encapsulate, protect, and release chemically unstable lipophilic food ingredients.

SLNs are typically fabricated by forming an oil-in-water nanoemulsion (NE) first, and then this system is cooled below the melting point of the dispersed lipid phase to induce crystallization [15]. In general, NEs can be produced using either high-energy or low-energy approaches [16]. High-energy approaches use specially designed mechanical devices (homogenizers) that generate intense energy fields to break up large lipid droplets into smaller ones. This type of approach is currently the most commonly used to fabricate NEs in the food industry, and the mechanical devices used include microfluidization, high-pressure homogenization, and sonication [16, 17]. High-energy approaches can be used to form nanoemulsions from a wide range of oils and emulsifiers, but they require dedicated homogenizers that must be purchased and maintained. In contrast, low-energy approaches do not need any specialized mechanical devices to form nanoemulsions. Instead, a nanoemulsion can simply be formed from certain surfactant, oil, and water mixtures by altering system composition or environmental conditions (such as temperature) in a specific way [18]. This approach mainly relies on inducing changes in surfactant properties, such as oil-water partitioning, optimum curvature, and packing characteristics, when system conditions are changed [18, 19]. A number of low-energy approaches have been developed to fabricate oil-in-water nanoemulsions, including spontaneous

73 emulsification, phase inversion temperature (PIT), and phase inversion composition (PIC) methods 
$[11,16,17]$.

At present, SLNs are usually fabricated using high-energy methods such as microfluidization, high-pressure homogenization, or sonication [15, 20-23]. Initially, NEs are prepared at a temperature above the melting point of the lipid phase, and then they are cooled below the crystallization point of the lipid phase to form SLNs [24]. In the current study, we examined the use of a low-energy method (PIT) to produce SLNs that might have application for the encapsulation, retention, and release of lipophilic bioactive components. The PIT method relies on changes in the properties of non-ionic surfactants when temperature is changed, such as their molecular geometry, packing, and oil-water partitioning $[18,25,26]$. The molecular geometry of a surfactant can be characterized by a packing parameter $(p)$ equal to the effective cross-sectional area of the hydrophobic tail $\left(a_{T}\right)$ divided by that of the hydrophilic head group $\left(a_{H}\right): p=a_{H} / a_{T}$ [27]. At relatively low temperatures $(\mathrm{T}<<\mathrm{PIT})$, the head groups of non-ionic surfactant molecules are highly hydrated, and so the area occupied by the head group is larger than that of the tail group $(p<1)$, which favors the formation of $\mathrm{O} / \mathrm{W}$ emulsions. At intermediate temperatures $(\mathrm{T} \approx \mathrm{PIT})$, the head groups become partially dehydrated so that the head group and tail group areas are approximately similar $(\mathrm{p} \approx 1)$, which favors the formation of a lamellar or a bicontinuous microemulsion phase [28]. At relatively high temperatures (T >PIT), the surfactant head groups become so dehydrated that their effective area is less than that of the tail group (p $>1)$, which favors the formation of W/O emulsions. This change in surfactant properties with temperature can be utilized to form nanoemulsions. A mixture of surfactant, oil, and water are heated to a temperature around or above the PIT, and then the system is rapidly cooled with continuous stirring, which induces the spontaneous formation of a nanoemulsion $[29,30]$. The formation of nanoemulsions with small droplets typically requires that the system is rapidly cooled with continuous stirring since this promotes the breakdown of the bicontinuous microemulsion phase formed at the PIT, and avoids rapid droplet coalescence just below the PIT [31, 32].

A number of previous studies have shown that SLNs can be formed using the PIT method. The influence of lipid and surfactant type on the ability of SLNs fabricated using this approach to

100 encapsulate lipophilic pharmaceutical agents has been reported [33-38]. The ability of PIT-SLNs to 101 improve the stability of an encapsulated nutraceutical ( $\beta$-carotene) against chemical degradation has 102 also been demonstrated [39]. A recent study showed that ultrafine (<10 nm) SLNs could be produced 103 using the PIT method that were suitable for topical application of biomarkers [40]. A recent in vitro 104 study suggested that PIT-SLNs may be suitable colloidal delivery systems for transporting lipophilic 105 bioactive agents across the Blood Brain Barrier [41]. 
In the current study, we aimed to utilize the PIT method to fabricate SLNs, and then to

107 investigate the role of storage temperature on their physical stability. We hypothesized that the

108 temperature the lipid nanoparticles were stored at relative to their melting/crystallization points and

109 PIT would influence their long-term stability. A model surfactant-oil-water (SOW) system was used to

110 facilitate a better understanding of the underlying physicochemical mechanisms involved. Thus, n-

111 octadecane was used as a model oil and Brij $30\left(\mathrm{C}_{12} \mathrm{E}_{4}\right)$ was used as a model non-ionic surfactant. The

112 approach used to form SLNs and LLNs using the PIT method is shown schematically in Figure 1. A

113 W/O emulsion was prepared by holding the SOW mixture at an initial temperature above the PIT with

114 continuous stirring. An O/W nanoemulsion was then formed by rapidly cooling the SOW mixture

115 below the PIT while continuing to stir. In some cases, the system was cooled to a final temperature

116 that was above the crystallization temperature of the emulsified lipid phase, which led to the formation

117 of LLNs. In other cases, the system was cooled to a final temperature that was below the

118 crystallization temperature of the emulsified phase, which led to the formation of SLNs. The resulting

119 colloidal dispersions were then stored at different temperatures to determine the influence of their

120 physical state and interfacial properties on their stability. Ultimately, the information gained from this

121 study will be useful for determining the optimum protocol for producing stable PIT-SLNs that might

122 be suitable for application in various types of commercial product.

\section{2. Materials and Methods}

\section{2.1. Materials}

125 Octadecane (99.5\% purity), $\mathrm{C}_{12} \mathrm{E}_{4}$ (Brij 30, Technical grade), and sodium benzoate (99\% purity)

126 were purchased from the Sigma-Aldrich Co. (St. Louis, MO). Citric acid (99\% purity) was purchased

127 from Fisher Scientific (St. Clair Shores, MI). All materials were used without further purification.

128 Double distilled water was used for the preparation of all solutions and nanoemulsions.

\section{2.2. Determination of Phase Inversion Temperature}

130 The PIT value was determined by monitoring the change in turbidity of surfactant-oil-water

131 systems during heating at a constant rate [42]. Coarse emulsions containing $20 \mathrm{wt} \%$ octadecane, $6 \mathrm{wt} \%$

132 Brij 30, and $74 \mathrm{wt} \%$ water phase $(\mathrm{pH} 3.0,0.8 \%$ citric acid, $0.08 \%$ sodium benzoate) were prepared by

133 mixing at ambient temperature using a magnetic stirrer. Turbidity versus temperature scans were then

134 measured for the SOW mixture using a UV/visible spectrophotometer at $600 \mathrm{~nm}$ (Ultra-spec 3000 pro,

135 Biochrom Ltd Cambridge, UK) with a temperature control module (Programmable Heated Cell

136 Holder, 80-2106-14, Biochrom Ltd., Cambridge, UK). Temperature control and data recording were 
137 carried out using computer software (Swift TM Melting Temp V1.09, Data Capture Software V1.02,

138 Biochrom Ltd., Cambridge, UK). The samples were contained within quartz cuvettes with a path

139 length of $1.0 \mathrm{~cm}$ and heated from $10^{\circ} \mathrm{C}$ at a rate of $1{ }^{\circ} \mathrm{C} \min ^{-1}$ with continuous stirring. Double-

140 distilled water was used as a blank.

\section{2.3. Lipid Nanoparticle Preparation}

142 Initially, the PIT of the SOW system was established using turbidity-temperature measurements as 143 described previously. Weighed amounts of oil, surfactant, and water were then gently mixed together 144 in a glass beaker and heated to an initial temperature $\left(50^{\circ} \mathrm{C}\right)$ above the PIT $\left(\approx 40^{\circ} \mathrm{C}\right)$ using a water bath. 145 After this temperature was reached, the mixture was held for 10 minutes and then split into four 146 samples in four beakers (preheated to $50^{\circ} \mathrm{C}$ ). The mixtures were continuously stirred using a 147 mechanical stirrer throughout the heating stage. The hot mixtures $\left(50^{\circ} \mathrm{C}\right)$ were then rapidly cooled to 148 different temperatures $\left(5^{\circ} \mathrm{C}\right.$ for the experimental group and $20^{\circ} \mathrm{C}, 25^{\circ} \mathrm{C}, 32^{\circ} \mathrm{C}$ for the control group) 149 using ice baths with continuous magnetic stirring. The liquid lipid nanoparticles (LLNs) in the control 150 group were then stored in temperature-controlled incubators at their formation temperatures. The solid 151 lipid nanoparticles (SLNs) in the experimental group $\left(5^{\circ} \mathrm{C}\right)$ were then split into four samples and 152 heated to different storage temperatures $\left(5,20,25\right.$ and $\left.32^{\circ} \mathrm{C}\right)$ in separate temperature-controlled 153 incubators. As a result the physical state of the lipid phase in the experimental group changed 154 depending on storage temperature.

\subsection{Particle Size Analysis}

156 The stability of the lipid nanoparticles was assessed by measuring changes in their mean particle 157 size and particle size distribution during storage. Particle size measurements were performed using a 158 dynamic light scattering (DLS) instrument (Zetasizer Nano ZS, Malvern Instruments, Malvern, UK).

159 To avoid multiple scattering effects samples were diluted 100 times using buffer solutions (pH 3.0) 160 maintained at temperatures corresponding to their storage temperatures. The DLS data are reported as 161 the Z-average mean diameter. The particle size of some samples was also assessed by a static light 162 scattering (SLS) instrument (Mastersizer 2000, Malvern Instruments, Malvern, UK), which is more 163 suitable for analyzing samples containing large particles. In this case, measurements were reported as

164 the volume-weighted mean diameter, $d_{43}=\sum n_{i} d_{i}^{4} / \sum n_{i} d_{i}^{3}$, where $n_{i}$ is the number of particles of 165 diameter $d_{i}$.

\section{2.5. Differential Scanning Calorimetry}

167 A differential scanning calorimeter (DSC; Q1000, TA Instruments, New Castle, DE) was used to 
study the thermal transformations of the emulsified lipid phases during heating-cooling cycles.

169 Emulsions (5-10 mg) were placed in hermetic aluminum pans and sealed, while sealed empty pans

170 were used as a reference. The heating and cooling rate was set at $20^{\circ} \mathrm{C} / \mathrm{min}$ for all samples. Different heat-cool cycles were used to study the crystallization and melting temperature of the emulsified lipid phase and to establish the physical state of lipid nanoparticles stored at $20^{\circ} \mathrm{C}$ :

173 - Crystallization and melting point determination: Lipid nanoparticles were prepared using the PIT

\subsection{Microstructure Analysis}

The microstructure of the samples was observed using optical microscopy (Nikon Eclipse 80i, Nikon Instrument Inc., Melville, NY) with the aid of a temperature-controlled stage (LTS 120) and a temperature controller (PE 94, Linkam Scientific Instruments Ltd., Tadworth, UK). Samples were pipetted onto a microscope slide, covered with a cover slip, and then placed on the temperaturecontrolled stage.

For determination of the microstructures of the surfactant-oil-water systems at temperatures (50, 40 and $20^{\circ} \mathrm{C}$ ) around the phase inversion temperature, samples were initially prepared by heating the mixtures to $50{ }^{\circ} \mathrm{C}$ with stirring. Images of the mixtures were then recorded at $50{ }^{\circ} \mathrm{C}$, and after they were cooled from 50 to $40^{\circ} \mathrm{C}$ at a rate of $10^{\circ} \mathrm{C} \mathrm{min}^{-1}$. The image of the mixture at $20^{\circ} \mathrm{C}$ was obtained by cooling the mixture from 50 to $20^{\circ} \mathrm{C}$ in a test tube with constant stirring (since this procedure is needed to form nanoemulsions).

For determination of the microstructures of the samples at different storage temperatures, images were obtained by placing an aliquot of the samples on microscope slides placed on the temperaturecontrolled stage set to the appropriate temperature.

\section{$195 \quad$ 2.7. Statistical Analysis}

All experiments were carried out in triplicate and the results are reported as means and standard deviations. Statistical differences were tested using statistical analysis software (Minitab 17, Minitab

198 Inc., State College, PA). A student's t-test was used to determine the statistical differences between two groups. Tukey's test was used in an analysis of variance (ANOVA) mode for the comparison of 
differences amongst more than two groups. In all cases, $P<0.05$ is considered a significant effect.

\section{Results and Discussions}

202

203

204

205

206

207

208

209

210

211

212

213

214

215

216

217

218

219

220

221

222

223

224

225

226

227

228

229

230

\subsection{Identification of Phase Inversion Temperature}

The PIT of the surfactant-oil-water (SOW) system used in this study was determined by measuring the change in turbidity with temperature. Initially, a coarse $\mathrm{O} / \mathrm{W}$ emulsion was prepared by stirring surfactant, oil, and water at ambient temperature, and then the turbidity was measured as the temperature of this mixture was increased from 10 to $50{ }^{\circ} \mathrm{C}$ at a controlled rate. The turbidity remained relatively high and constant from 10 to $38^{\circ} \mathrm{C}$ and the system had an opaque appearance, which can be attributed to strong light scattering by the relatively large droplets in the coarse $\mathrm{O} / \mathrm{W}$ emulsion (Figure 2a). The formation of an $\mathrm{O} / \mathrm{W}$ emulsion is preferred at lower temperatures because the surfactant head groups are highly hydrated, and so that their cross-sectional areas are appreciably larger than those of their tail groups [43]. From 39 to $40{ }^{\circ} \mathrm{C}$, the turbidity fell steeply and the samples had a translucent appearance (Figure 2a), which is indicative of the formation of a bicontinuous microemulsion. In this temperature range, taken to correspond to the PIT, the cross-sectional areas of the surfactant head and tail groups are nearly balanced, which favors a surfactant monolayer curvature close to zero thereby facilitating bicontinuous microemulsion formation [28]. Upon further heating, the samples became highly turbid with an opaque appearance (Figure 2a). At these higher temperatures, the surfactant head groups become highly dehydrated so that their cross-sectional areas were less than that of their tail groups, which favors the formation of W/O emulsions [27]. During cooling, a steep decrease in turbidity was observed when the temperature fell below $40{ }^{\circ} \mathrm{C}$ and the samples became translucent (Figure 2a), which was again attributed to the formation of a bicontinuous microemulsion [32]. Upon further cooling, there was a steep increase in turbidity and the samples became opaque (Figure 2a), which can be attributed to rapid droplet coalescence just below the PIT leading to the formation of large particles that scatter light strongly [32]. There was a difference in the range of temperatures where the bicontinuous microemulsion was formed during the heating and cooling processes due to hysteresis effects, such as the finite time required for the samples to reach the incubation temperatures and the presence of an activation energy between the emulsion and microemulsion systems.

Optical microscopy images of the samples at different temperatures clearly indicated that they underwent appreciable microstructural changes that were consistent with the turbidity measurements. The optical microscopy images suggested that a water-in-oil emulsion containing relatively large 
droplets was formed at $50{ }^{\circ} \mathrm{C}$, a microemulsion phase was formed at $40{ }^{\circ} \mathrm{C}$, and an oil-in-water

232 nanoemulsion containing small droplets was formed at $20^{\circ} \mathrm{C}$ (Figure $\mathbf{2 b}$ ). Overall, these results

233 suggest that the PIT of the SOW used in this work was around 30 to $40{ }^{\circ} \mathrm{C}$ [42]. It should be noted

234 that measurements of the electrical conductivity of SOW systems are also commonly used to determine

235 their PIT, but we showed in a previous study that there was a good correlation between the PIT

236 determined by turbidity and conductivity measurements for similar systems [44], and so we only used

237 turbidity measurements here.

\section{3.2. Thermal Behavior of Emulsified Oil Phase}

239 The crystallization and melting points of the emulsified lipid phase were determined using DSC.

240 Initially, a nanoemulsion was prepared by heating a SOW mixture above the PIT, and then rapidly

241 cooling to ambient temperature (which is above the crystallization temperature). Then the sample was

242 loaded into a DSC pan, placed in the instrument, and cooled to $5^{\circ} \mathrm{C}$. A heat-cool cycle was then

243 applied to the sample, which involved heating to $60^{\circ} \mathrm{C}$ and then cooling back to $5^{\circ} \mathrm{C}$, and the change

244 in heat flow with temperature was monitored using DSC (Figure 3). During heating, a single

245 endothermic peak was observed around $26^{\circ} \mathrm{C}$, which can be attributed to the melting of the crystalline

246 octadecane droplets [45]. The melting temperature of the emulsified octadecane was slightly below

247 that of bulk octadecane $\left(28^{\circ} \mathrm{C}\right)$, which can be attributed to the influence of confinement effects on the

248 thermodynamic phase transition temperature [46, 47]. During cooling, a large exothermic peak was

249 observed around $8{ }^{\circ} \mathrm{C}$, which can be attributed to crystallization of the emulsified oil phase. The fact

250 that the emulsified octadecane crystallized at a much lower temperature than the bulk octadecane can

251 be attributed to substantial supercooling effects [48, 49]. Bulk oils usually contain catalytic impurities

252 that promote the formation of nuclei within the oil phase, whereas it is highly unlikely to find one of

253 these impurities inside very small oil droplets. Consequently, crystallization tends to be preceded by

254 heterogeneous nucleation in bulk oils, but by homogeneous nucleation in emulsified oils [50]. In

255 summary, the DSC measurements indicated that LLNs would remain in a liquid state when maintained

256 at temperatures exceeding about $12{ }^{\circ} \mathrm{C}$, and SLNs would remain in a solid state when kept at

257 temperatures below about $23^{\circ} \mathrm{C}$ (Figure 3).

258 3.3. Effect of Storage Temperatures on Solid and Liquid Lipid Nanoparticles

259 SLNs and LLNs were fabricated by controlling the thermal history of lipid nanoparticles formed 260 using the PIT method (Figure 1). SLNs were fabricated by cooling SOW systems from a temperature $261\left(50^{\circ} \mathrm{C}\right)$ above the PIT to a temperature $\left(5^{\circ} \mathrm{C}\right)$ below the crystallization point to completely crystallize 262 the lipid phase. The SLNs were then stored at temperatures below $\left(5\right.$ and $\left.20^{\circ} \mathrm{C}\right)$, around $\left(25^{\circ} \mathrm{C}\right)$ and 
263 above $\left(32^{\circ} \mathrm{C}\right)$ their melting temperature. As a control group, LLNs were produced by directly cooling 264 the SOW mixtures from $50^{\circ} \mathrm{C}$ to similar storage temperatures $\left(20,25\right.$, and $\left.32{ }^{\circ} \mathrm{C}\right)$ as the SLNs. The 265 effect of storage temperature on the lipid nanoparticles was examined by measuring their mean particle size (Figure 4) and studying their microstructure (Figure 5) before and after 24 hours incubation.

For the SLNs, the mean particle diameters of the nanoparticles were initially relatively small at 5 and $20^{\circ} \mathrm{C}(d \approx 109$ and $128 \mathrm{~nm}$, respectively) and did not change appreciably after 24 hours of storage. These measurements indicated that it was possible to produce SLNs (i.e., $d<200 \mathrm{~nm}$ ) using the PIT method and that SLNs stored well below their melting temperature were stable to particle growth in the short-term. However, examination of the SOW systems using optical microscopy showed that the SLNs did not exist as individual solid particles as expected (Figure 1), but actually formed complex aggregated structures (Figure 5a). These structures may have formed due to the relatively high surfactant levels used leading to depletion flocculation $[51,52]$. The fact that an increase in particle size was not observed by light scattering can be attributed to the fact that the flocs became dissociated when the samples were diluted prior to making the measurements.

When the SLNs were held at higher temperatures there was an appreciable increase in mean particle diameter, which is indicative of particle growth and/or aggregation, which may have occurred due to morphology changes, flocculation, coalescence, or partial coalescence (Figures $\mathbf{4}$ and 5b). The SLNs stored at $25^{\circ} \mathrm{C}$ were highly unstable to aggregation, and gelation was observed in the overall system after 24 hours storage, i.e., the samples did not flow when the test tubes were inverted. In addition, the optical microscopy images indicated that the system consisted of large irregularly shaped structures that were associated with each other (Figure 5b). This effect may have occurred due to the formation of a network of aggregated lipid particles caused by partial coalescence [24, 53]. Partial coalescence occurs when the lipid droplets are only partly crystalline so that a crystal in one droplet can penetrate into the liquid portion of another droplet [48]. Electron microscopy studies have previously demonstrated the formation of a particle network formation in systems containing partially crystalline hydrocarbon nanoparticles [54]. The fact that the system contained large irregularly shaped particles, rather than small spherical lipid particles similar to those in the initial samples, suggests that there was a large morphology change associated with droplet crystallization. A recent study reported that hydrocarbon droplets may form a variety of shapes after crystallizing depending on holding temperature and cooling rates [55], which is consistent with our data.

Appreciable particle aggregation was also observed when the SLNs were stored at $32{ }^{\circ} \mathrm{C}$, but gelation was not observed in this case (Figure 5c). This temperature is appreciably above the melting point of the lipid nanoparticles, and therefore the lipid phase will have been completely liquid. In this 
case, the increase in particle size was most likely due to accelerated droplet coalescence at temperatures just below the PIT [56]. When the optimum curvature of the surfactant monolayer favors an $\mathrm{O} / \mathrm{W}$ emulsion, but is still fairly close to unity, then the droplet surfaces are highly mobile and prone to coalescence [57].

For the LLNs, the lipid nanoparticles exhibited a relatively small amount of growth when stored at $20^{\circ} \mathrm{C}$ for 24 hours as seen in the light scattering (Figure 4) and optical microscopy images (Figure 5a). Small droplets were present immediately after nanoemulsion formation ( 0 hours) but their dimensions increased after 24 hours incubation. This effect may have occurred because the storage temperature was not sufficiently below the phase inversion temperature, which led to coalescence.

Extensive particle growth and gelation were observed when the samples were stored at $25^{\circ} \mathrm{C}$ (Figures 4 and 5b). One might not have expected partial coalescence to occur for the LLNs because the droplets were initially completely liquid. However, droplet coalescence may have occurred during storage since the temperature was still fairly close to the PIT, which led to an increase in droplet size, and thus the chance of finding catalytic impurities within the oil droplets increased [48]. As a result, heterogeneous nucleation (rather than homogeneous nucleation) occurred within the lipid phase leading to the formation of octadecane crystals that promoted partial coalescence and gelation. The

313 and 5c), which can again be attributed to the fact that the storage temperature was quite close to the

314 PIT, which promoted accelerated droplet coalescence [56].

\section{3.4. Storage Stability of Solid and Liquid Nanoparticles}

Finally, we measured the long-term storage stability of the lipid nanoparticles found to be the most stable in the short-term stability studies: SLNs at 5 and $20^{\circ} \mathrm{C}$ and LLNs at $20^{\circ} \mathrm{C}$. DSC was used to confirm the physical states of the lipid nanoparticles in the LLNs and SLNs at $20^{\circ} \mathrm{C}$ at the beginning of the storage studies. The two samples were heated from 20 to $60^{\circ} \mathrm{C}$ in the DSC instrument to monitor if any melting transition occurred (Figure 6). During heating, an endothermic peak associated with lipid phase melting was observed for the SLNs, but no peak was observed for the LLNs, which confirmed that the SLNs initially contained solid particles whereas the LLNs initially contained liquid ones. To monitor the storage stability of the SLNs and LLNs, the change in mean particle size and particle size distribution was recorded over time. The SLNs were relatively stable to particle growth throughout 8 days of storage at both at 5 and $20^{\circ} \mathrm{C}$, with little increase in mean particle diameter 
account for this effect. Conversely, the LLNs exhibited an appreciable increase in mean particle size during storage (Figure 7) and the particle size distribution changed appreciably (Figure 8c). As discussed earlier, the increase in droplet size for the LLNs during storage can be attributed to droplet coalescence when the storage temperature is not sufficiently far below the PIT [57]. These results

332 highlight the critical importance of storage temperature for ensuring the stability of lipid nanoparticles

333 fabricated using the PIT method.

\section{Conclusions}

We have shown that both LLNs and SLNs can be produced by the PIT method using model surfactant $\left(\mathrm{C}_{12} \mathrm{E}_{4}\right)$ / oil (octadecane) / water systems by altering their thermal history. The effect of storage temperature on the stability of the lipid nanoparticles was examined by holding them at different temperatures and monitoring changes in their particle size. The lipid nanoparticles were unstable when the storage temperature was above the melting temperature of the emulsified lipid phase, which was attributed to rapid coalescence at temperatures just below the PIT. This problem may be overcome by using an SOW system that has a PIT temperature that is appreciably above the intended storage temperature of the lipid nanoparticles. The lipid nanoparticles tended to aggregate and gel when the storage temperature was around the melting temperature of the emulsified lipid phase, which was attributed to an appreciable change in particle morphology and partial coalescence. Using a lipid phase that is not partially crystalline at the intended storage temperature may alleviate this problem. SLNs stored at temperatures well below the melting temperature of the lipid phase were relatively stable to particle growth during storage. This effect may be because completely solid particles are stable to both coalescence and partial coalescence. In summary, this study provides some useful insights into the formation and storage of LLNs and SLNs fabricated using the PIT method. These lipid nanoparticles may be used as colloidal delivery systems for lipophilic active ingredients for industrial applications, such as pharmaceuticals, nutraceuticals, or supplements.

\section{Acknowledgements}

This material was partly based upon work supported by the Cooperative State Research, Extension, Education Service, USDA, Massachusetts Agricultural Experiment Station (Project No. 831) and USDA, NRI Grants (2014-67021).

\section{Literature Cited}

[1] P.M. Kris-Etherton, W.S. Harris, L.J. Appel, Fish consumption, fish oil, omega-3 fatty acids, and 
cardiovascular disease, circulation, 106 (2002) 2747-2757.

359 [2] P.M. Kris-Etherton, K.D. Hecker, A. Bonanome, S.M. Coval, A.E. Binkoski, K.F. Hilpert, A.E.

360 Griel, T.D. Etherton, Bioactive compounds in foods: their role in the prevention of cardiovascular

361 disease and cancer, The American journal of medicine, 113 (2002) 71-88.

362 [3] Y.M. Jeanes, W.L. Hall, S. Ellard, E. Lee, J.K. Lodge, The absorption of vitamin E is influenced by

363 the amount of fat in a meal and the food matrix, British journal of nutrition, 92 (2004) 575-579.

364 [4] M.L. Nguyen, S.J. Schwartz, Lycopene stability during food processing, Experimental Biology and 365 Medicine, 218 (1998) 101-105.

366 [5] J. Weiss, E.A. Decker, D.J. McClements, K. Kristbergsson, T. Helgason, T. Awad, Solid lipid 367 nanoparticles as delivery systems for bioactive food components, Food Biophysics, 3 (2008) 146-154.

368 [6] K. Westesen, H. Bunjes, M. Koch, Physicochemical characterization of lipid nanoparticles and

369 evaluation of their drug loading capacity and sustained release potential, Journal of controlled release, 37048 (1997) 223-236.

371 [7] M. Schubert, C. Müller-Goymann, Characterisation of surface-modified solid lipid nanoparticles

372 (SLN): influence of lecithin and nonionic emulsifier, European journal of pharmaceutics and

373 biopharmaceutics, 61 (2005) 77-86.

374 [8] V. Jenning, A.F. Thünemann, S.H. Gohla, Characterisation of a novel solid lipid nanoparticle

375 carrier system based on binary mixtures of liquid and solid lipids, International Journal of

376 Pharmaceutics, 199 (2000) 167-177.

377 [9] C. Puglia, A. Offerta, C. Carbone, F. Bonina, R. Pignatello, G. Puglisi, Lipid Nanocarriers (LNC)

378 and their Applications in Ocular Drug Delivery, Current Medicinal Chemistry, 22 (2015) 1589-1602.

379 [10] M. Patel, E.B. Souto, K.K. Singh, Advances in brain drug targeting and delivery: limitations and

380 challenges of solid lipid nanoparticles, Expert Opinion on Drug Delivery, 10 (2013) 889-905.

381 [11] N. Anton, J.P. Benoit, P. Saulnier, Design and production of nanoparticles formulated from nano-

382 emulsion templates - A review, Journal of Controlled Release, 128 (2008) 185-199. 
384 Surface A, 353 (2010) 149-156.

385 [13] T.S. Awad, T. Helgason, J. Weiss, E.A. Decker, D.J. McClements, Effect of Omega-3 Fatty Acids 386 on Crystallization, Polymorphic Transformation and Stability of Tripalmitin Solid Lipid Nanoparticle

387 Suspensions, Crystal Growth \& Design, 9 (2009) 3405-3411.

388 [14] A. Hentschel, S. Gramdorf, R.H. Muller, T. Kurz, beta-Carotene-loaded nanostructured Lipid 389 carriers, J Food Sci, 73 (2008) N1-N6.

390 [15] R.H. Muller, K. Mader, S. Gohla, Solid lipid nanoparticles (SLN) for controlled drug delivery-a

391 review of the state of the art, European journal of pharmaceutics and biopharmaceutics, 50 (2000) 161-

392177.

393 [16] D.J. McClements, J. Rao, Food-Grade Nanoemulsions: Formulation, Fabrication, Properties,

394 Performance, Biological Fate, and Potential Toxicity, Critical Reviews in Food Science and Nutrition, $39551(2011) 285-330$.

396 [17] A.A. Date, N. Desai, R. Dixit, M. Nagarsenker, Self-nanoemulsifying drug delivery systems:

397 Formulation insights, applications and advances, Nanomedicine, 5 (2010) 1595-1616.

398 [18] N. Anton, T.F. Vandamme, The universality of low-energy nano-emulsification, International 399 Journal of Pharmaceutics, 377 (2009) 142-147.

400 [19] K. Shinoda, S. Friberg, Emulsions and Solubilization, Wiley Interscience, New York, 1986.

401 [20] T. Helgason, T.S. Awad, K. Kristbergsson, E.A. Decker, D.J. McClements, J. Weiss, Impact of 402 surfactant properties on oxidative stability of $\beta$-carotene encapsulated within solid lipid nanoparticles, 403 Journal of agricultural and food chemistry, 57 (2009) 8033-8040.

404 [21] C. Qian, E.A. Decker, H. Xiao, D.J. McClements, Impact of lipid nanoparticle physical state on 405 particle aggregation and $\beta$-carotene degradation: Potential limitations of solid lipid nanoparticles, Food 406 Research International, 52 (2013) 342-349.

407 [22] A.C. Silva, E. Gonzalez-Mira, M.L. Garcia, M.A. Egea, J. Fonseca, R. Silva, D. Santos, E.B. 
Souto, D. Ferreira, Preparation, characterization and biocompatibility studies on risperidone-loaded

409 solid lipid nanoparticles (SLN): High pressure homogenization versus ultrasound, Colloids and

410 Surfaces B-Biointerfaces, 86 (2011) 158-165.

411 [23] S. Martins, I. Tho, D.C. Ferreira, E.B. Souto, M. Brandl, Physicochemical properties of lipid

412 nanoparticles: Effect of lipid and surfactant composition, Drug Development and Industrial Pharmacy, $41337(2011) 815-824$.

414 [24] W. Mehnert, K. Mader, Solid lipid nanoparticles - Production, characterization and applications, 415 Advanced Drug Delivery Reviews, 47 (2001) 165-196.

416 [25] K. Shinoda, H. Arai, Correlation between phase inversion temperature in emulsion + cloud point 417 in solution of nonionic emulsifier, Journal of Physical Chemistry, 68 (1964) 3485-\&.

418 [26] K. Shinoda, H. Saito, The effect of temperature on the phase equilibria and the types of

419 dispersions of the ternary system composed of water, cyclohexane, and nonionic surfactant, Journal of 420 Colloid and Interface Science, 26 (1968) 70-74.

421 [27] J.N. Israelachvili, Intermolecular and surface forces: revised third edition, Academic press2011.

422 [28] F. Leal-Calderon, V. Schmitt, J. Bibette, Emulsion science: basic principles, Second Edition ed., 423 Springer Verlag2007.

424 [29] D. Morales, J.M. Gutierrez, M.J. Garcia-Celma, Y.C. Solans, A study of the relation between 425 bicontinuous microemulsions and oil/water nano-emulsion formation, Langmuir, 19 (2003) 7196-7200.

426 [30] P. Izquierdo, J. Esquena, T.F. Tadros, C. Dederen, M. Garcia, N. Azemar, C. Solans, Formation 427 and stability of nano-emulsions prepared using the phase inversion temperature method, Langmuir, 18 $428 \quad$ (2002) 26-30.

429 [31] K. Shinoda, H. Saito, Stability of O/W type emulsions as functions of temperature and HLB of 430 emulsifiers - emulsification by PIT-method, Journal of Colloid and Interface Science, 30 (1969) 258$431 \&$.

432 [32] K. Roger, B. Cabane, U. Olsson, Formation of 10-100 nm Size-Controlled Emulsions through a 
Sub-PIT Cycle, Langmuir, 26 3860-3867.

434 [33] L. Montenegro, C. Sinico, I. Castangia, C. Carbone, G. Puglisi, Idebenone-loaded solid lipid

435 nanoparticles for drug delivery to the skin: In vitro evaluation, International Journal of Pharmaceutics, $436434(2012) 169-174$.

437 [34] M.G. Sarpietro, M.L. Accolla, G. Puglisi, F. Castelli, L. Montenegro, Idebenone loaded solid lipid 438 nanoparticles: Calorimetric studies on surfactant and drug loading effects, International Journal of 439 Pharmaceutics, 471 (2014) 69-74.

440 [35] P. Wasutrasawat, H. Al-Obaidi, S. Gaisford, M.J. Lawrence, W. Warisnoicharoen, Drug 441 solubilisation in lipid nanoparticles containing high melting point triglycerides, European Journal of 442 Pharmaceutics and Biopharmaceutics, 85 (2013) 365-371.

443 [36] J.F. Fangueiro, T. Andreani, L. Fernandes, M.L. Garcia, M.A. Egea, A.M. Silva, E.B. Souto, 444 Physicochemical characterization of epigallocatechin gallate lipid nanoparticles (EGCG-LNs) for 445 ocular instillation, Colloids and Surfaces B-Biointerfaces, 123 (2014) 452-460.

446 [37] C. Carbone, A. Campisi, T. Musumeci, G. Raciti, R. Bonfanti, G. Puglisi, FA-loaded lipid drug 447 delivery systems: Preparation, characterization and biological studies, European Journal of 448 Pharmaceutical Sciences, 52 (2014) 12-20.

449 [38] C. Carbone, B. Tomasello, B. Ruozi, M. Renis, G. Puglisi, Preparation and optimization of PIT 450 solid lipid nanoparticles via statistical factorial design, European Journal of Medicinal Chemistry, 49 $451 \quad$ (2012) 110-117.

452 [39] L. Zhang, D.G. Hayes, G. Chen, Q. Zhong, Transparent Dispersions of Milk-Fat-Based 453 Nanostructured Lipid Carriers for Delivery of beta-Carotene, Journal of Agricultural and Food 454 Chemistry, 61 (2013) 9435-9443.

455 [40] X. Calderon-Colon, M.W. Patchan, M.L. Theodore, H.T. Le, J.L. Sample, J.J. Benkoski, J.B.

456 Patrone, Synthesis of sub-10 nm solid lipid nanoparticles for topical and biomarker detection 457 applications, Journal of Nanoparticle Research, 16 (2014). 
Barrier of Idebenone-Loaded Solid Lipid Nanoparticles, Journal of Nanoscience and Nanotechnology,

$46012(2012) 330-337$.

461 [42] O.G. Jones, E.A. Decker, D.J. McClements, Formation of biopolymer particles by thermal

462 treatment of beta-lactoglobulin-pectin complexes, Food Hydrocolloids, 23 (2009) 1312-1321.

463 [43] D.J. McClements, Edible nanoemulsions: fabrication, properties, and functional performance, Soft

464 Matter, 7 (2011) 2297-2316.

465 [44] J.J. Rao, D.J. McClements, Stabilization of Phase Inversion Temperature Nanoemulsions by

466 Surfactant Displacement, Journal of Agricultural and Food Chemistry, 58 (2010) 7059-7066.

467 [45] P. Walstra, Physical Chemistry of Foods, Marcel Decker, New York, NY., 2003.

468 [46] X. Gao, Y.L. Su, B.Q. Xie, D.S. Fu, D.J. Wang, Progress in Studies of Confined Crystallzaiton of

469 Long-chain n-Alkanes, Acta Polymerica Sinica, (2014) 22-30.

470 [47] E.V. Fette, A. Pham, T. Adalsteinsson, Crystallization and melting transitions of hexadecane

471 droplets in polystyrene nanocapsules, Journal of Physical Chemistry B, 112 (2008) 5403-5411.

472 [48] J.N. Coupland, Crystallization in emulsions, Current Opinion in Colloid \& Interface Science, 7

473 (2002) 445-450.

474 [49] P. Thanasukarn, R. Pongsawatmanit, D.J. McClements, Impact of fat and water crystallization on 475 the stability of hydrogenated palm oil-in-water emulsions stabilized by whey protein isolate, Colloid

476 Surface A, 246 (2004) 49-59.

477 [50] D. Clausse, F. Gomez, I. Pezron, L. Komunjer, C. Dalmazzone, Morphology characterization of

478 emulsions by Differential Scanning Calorimetry, Advances in Colloid and Interface Science, 117

479 (2005) 59-74.

480 [51] J. Bibette, D. Roux, B. Pouligny, Creaming of emulsions - the role of depletion forces induced by

481 surfactant, Journal De Physique Ii, 2 (1992) 401-424.

482 [52] D.J. McClements, Ultrasonic determination of depletion flocculation in oil-in-water emulsions 
483 containing a nonionic surfactant, Colloid Surface A, 90 (1994) 25-35.

484 [53] T. Helgason, T. Awad, K. Kristbergsson, D.J. McClements, J. Weiss, Effect of surfactant surface 485 coverage on formation of solid lipid nanoparticles (SLN), Journal of Colloid and Interface Science, $486334(2009) 75-81$.

487 [54] G.L. Cramp, A.M. Docking, S. Ghosh, J.N. Coupland, On the stability of oil-in-water emulsions 488 to freezing, Food Hydrocolloids, 18 (2004) 899-905.

489 [55] N. Denkov, S. Tcholakova, I. Lesov, D. Cholakova, S.K. Smoukov, Self-shaping of oil droplets 490 via the formation of intermediate rotator phases upon cooling, Nature, 528 (2015) 392-+.

491 [56] A. Kabalnov, H. Wennerström, Macroemulsion stability: the oriented wedge theory revisited, 492 Langmuir, 12 (1996) 276-292.

493 [57] A. Kabalnov, H. Wennerstrom, Macroemulsion stability: The oriented wedge theory revisited, 494 Langmuir, 12 (1996) 276-292. 


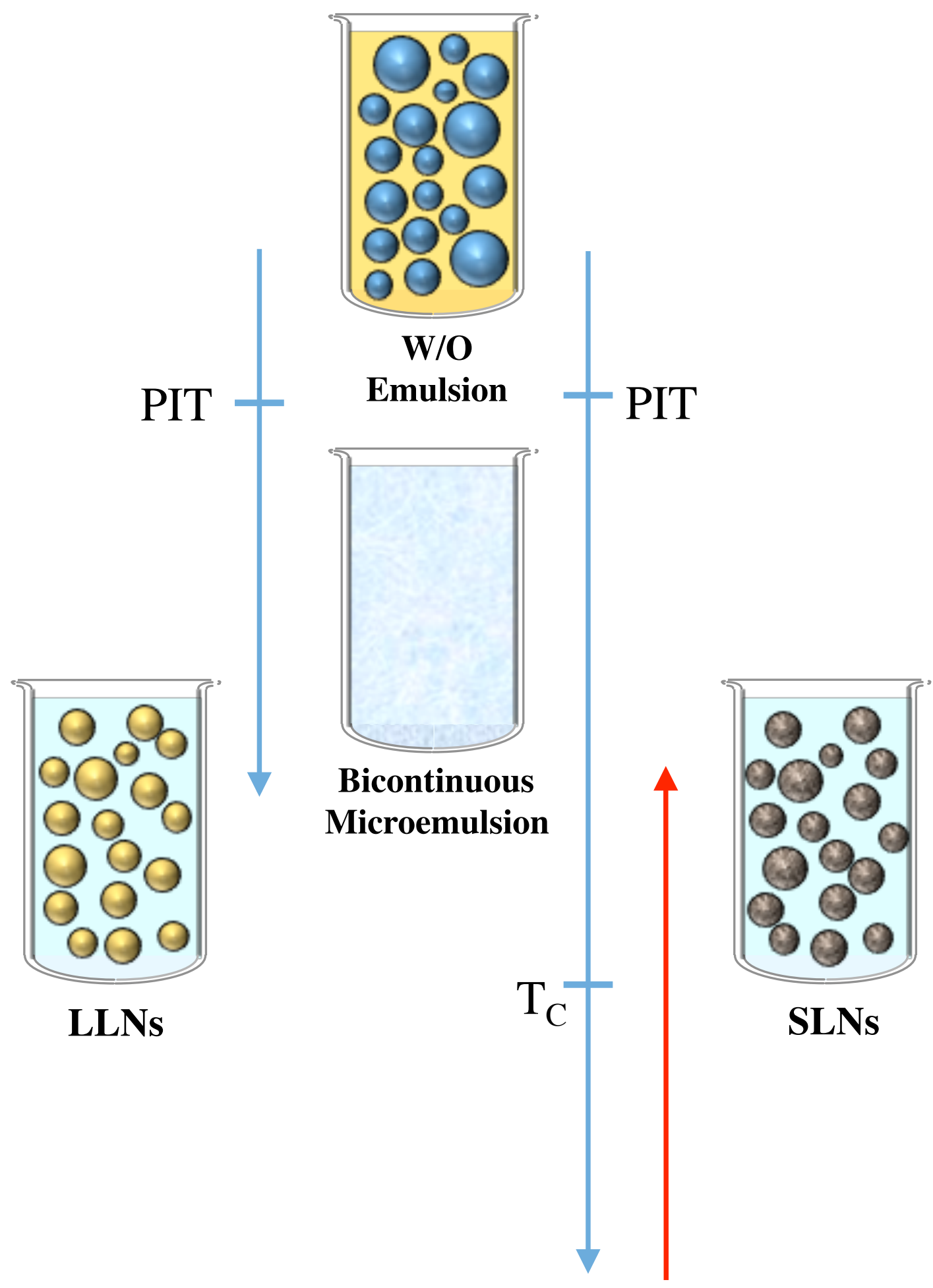

Figure 1: Schematic representation of formation of SLNs and LLNs using the PIT method. LLNs are formed by cooling SOW mixtures below the PIT but above the droplet crystallization temperature, whereas SLNs are formed by cooling below the PIT and droplet crystallization temperature. 


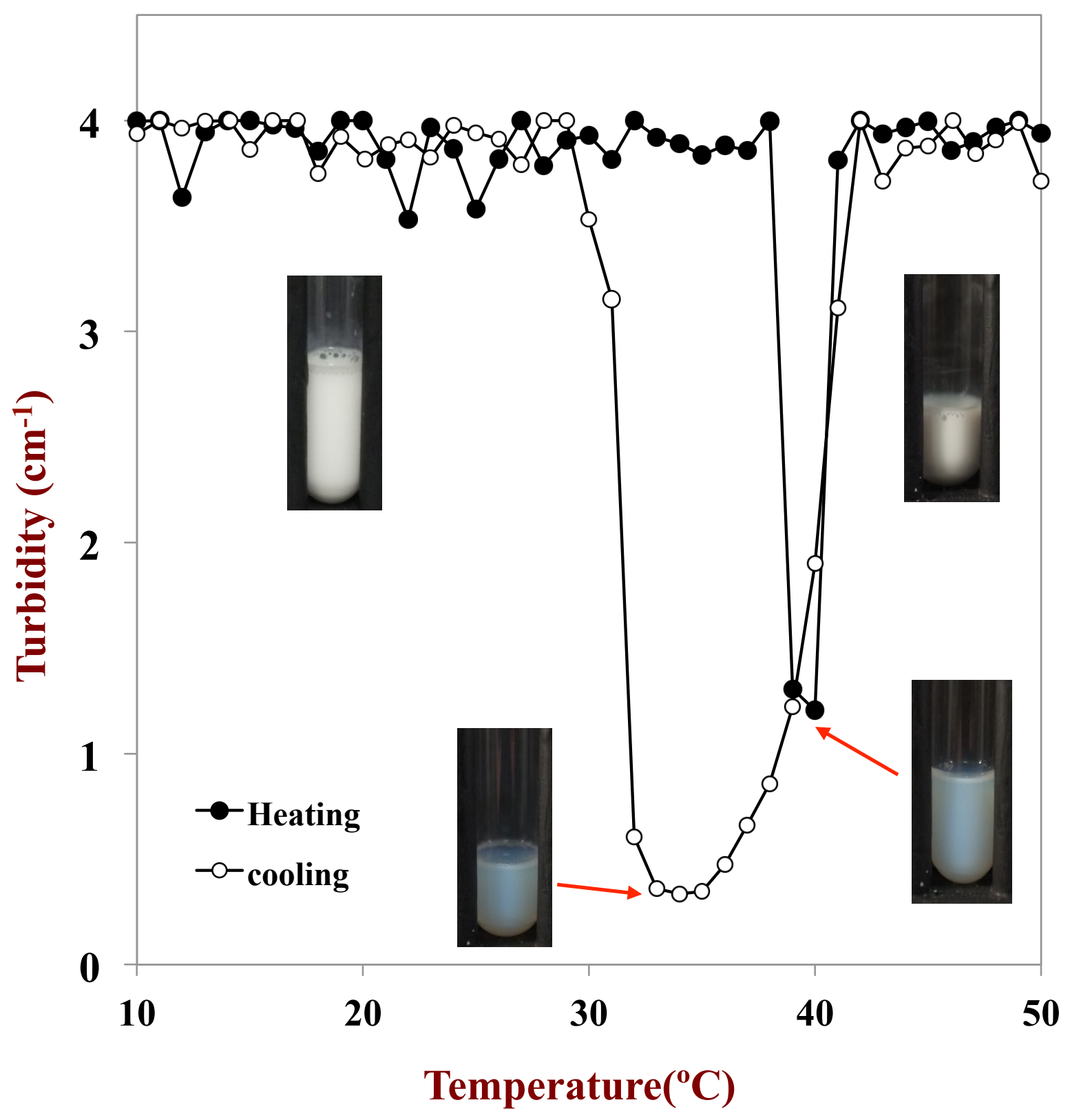

Figure 2a: Temperature dependence of the turbidity of the surfactant/oil/water system (20 wt. \% octadecane, 6 wt. \% Brij 30, 74 wt. \% pH 3 buffer solution) during heating and cooling at a controlled rate of $1^{\circ} \mathrm{C} \mathrm{min}^{-1}$. 


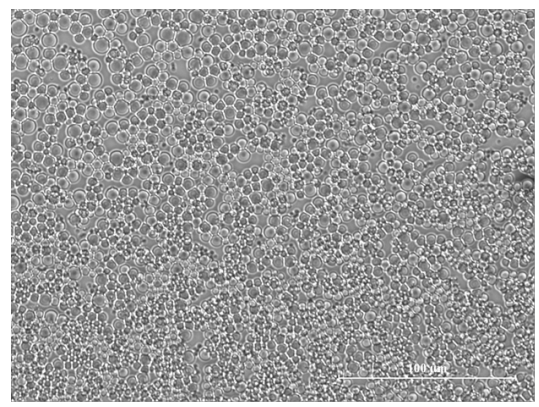

$50{ }^{\circ} \mathrm{C}$

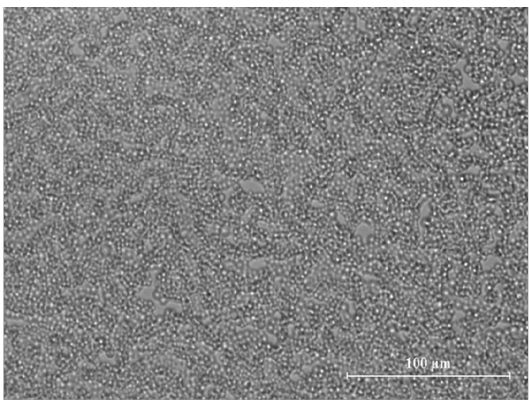

$40{ }^{\circ} \mathrm{C}$

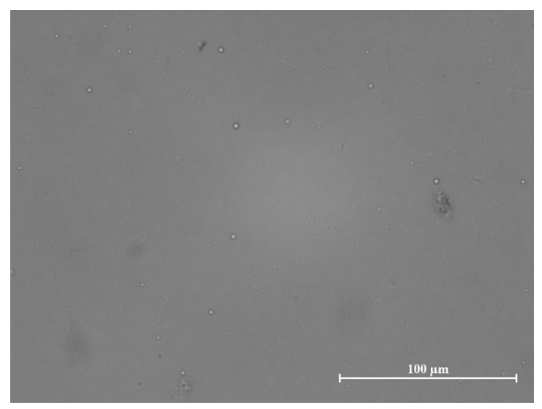

$20{ }^{\circ} \mathrm{C}$

Figure 2b: Temperature dependence of the microstructure of the surfactant/oil/water system (20 wt. $\%$ octadecane, 6 wt. $\%$ Brij 30,74 wt. $\%$ pH 3 buffer solution) at $50{ }^{\circ} \mathrm{C}, 40{ }^{\circ} \mathrm{C}$ and $20^{\circ} \mathrm{C}$ upon cooling. 


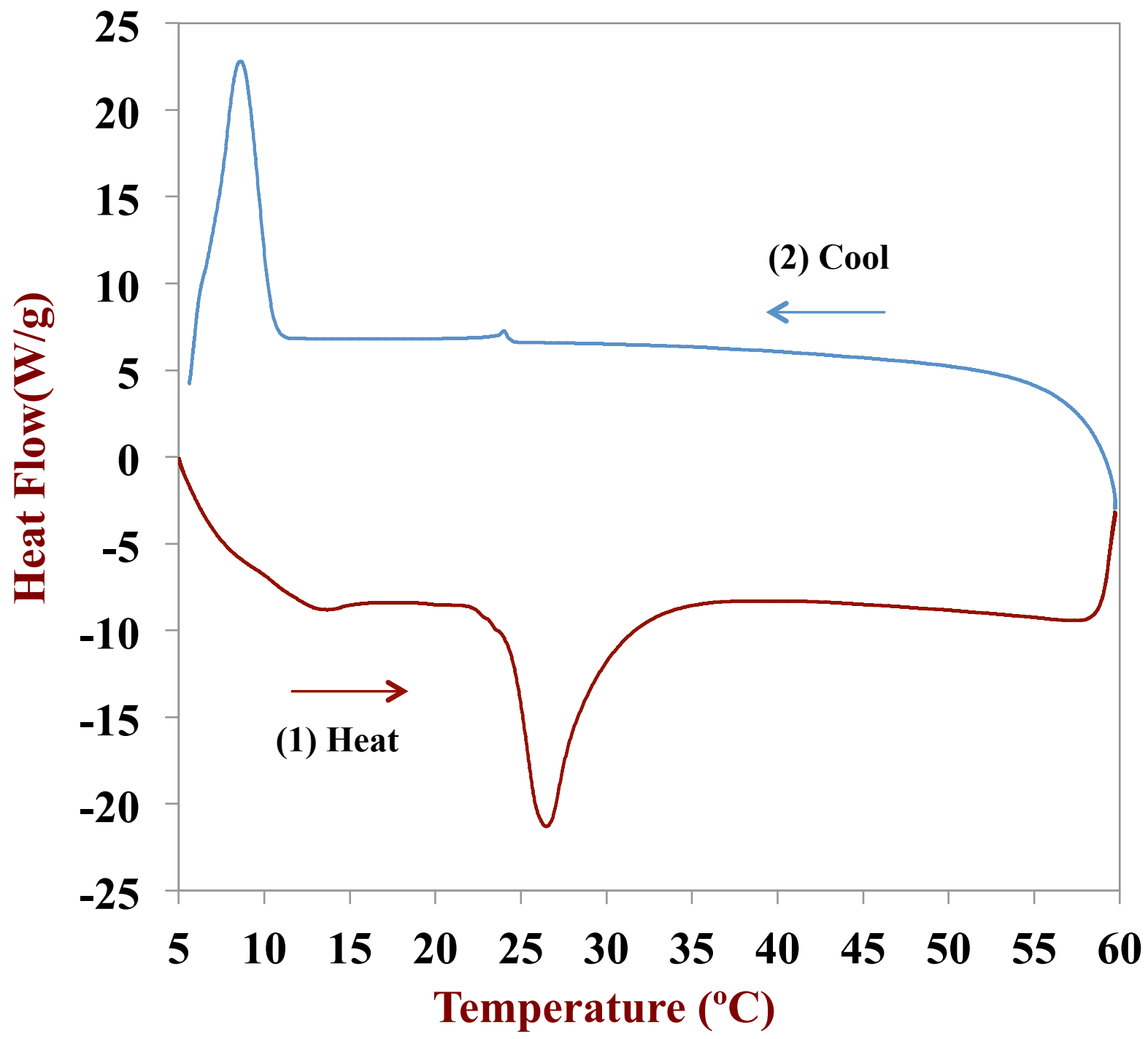

Figure 3: DSC profiles of emulsified oil phases of the surfactant/oil/water system during heating and cooling at a controlled rate of $20^{\circ} \mathrm{C} \mathrm{min}^{-1}$. 


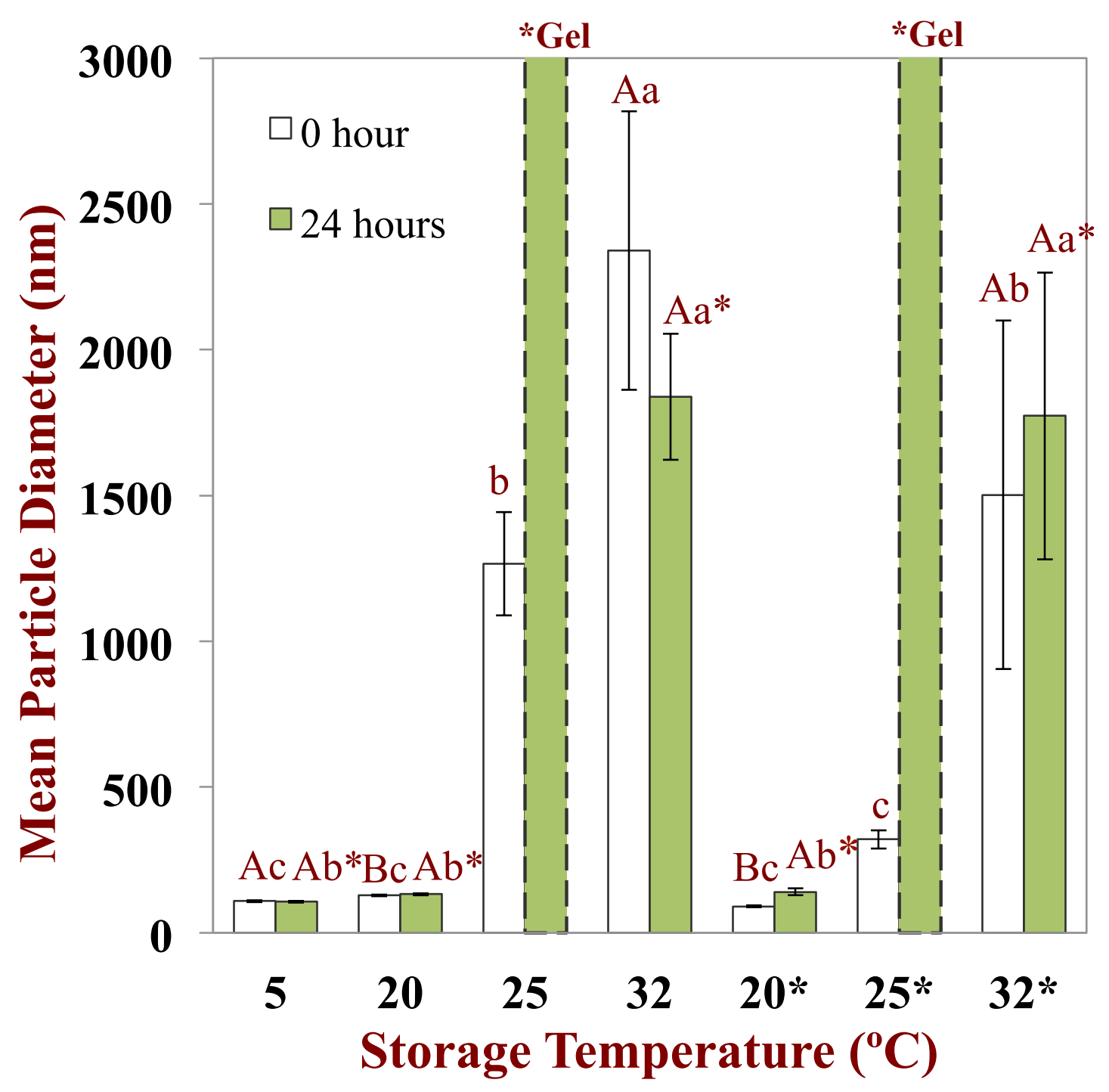

Figure 4: Mean particle diameters of emulsions with different thermal histories and storage temperatures after 0 and 24 hours. Emulsions were prepared by cooling rapidly from 50 to $5^{\circ} \mathrm{C}$ to form SLNs, and then heating to $5,20,25,32$ or by cooling directly from $50^{\circ} \mathrm{C}$ to $20^{*}, 25^{*}$, $32 *$ to form LLNs. For both groups, the emulsions at $25^{\circ} \mathrm{C}$ became gels after 24 hours storage. Statistical differences of the means are shown between 0 hour and 24 hours for each sample (A, B) and among different samples at 0 hour $(a, b, c)$ or 24 hours $\left(a^{*}, b^{*}, c^{*}\right)$ were tested. Means with different letters are significantly different $(P<0.05)$. 

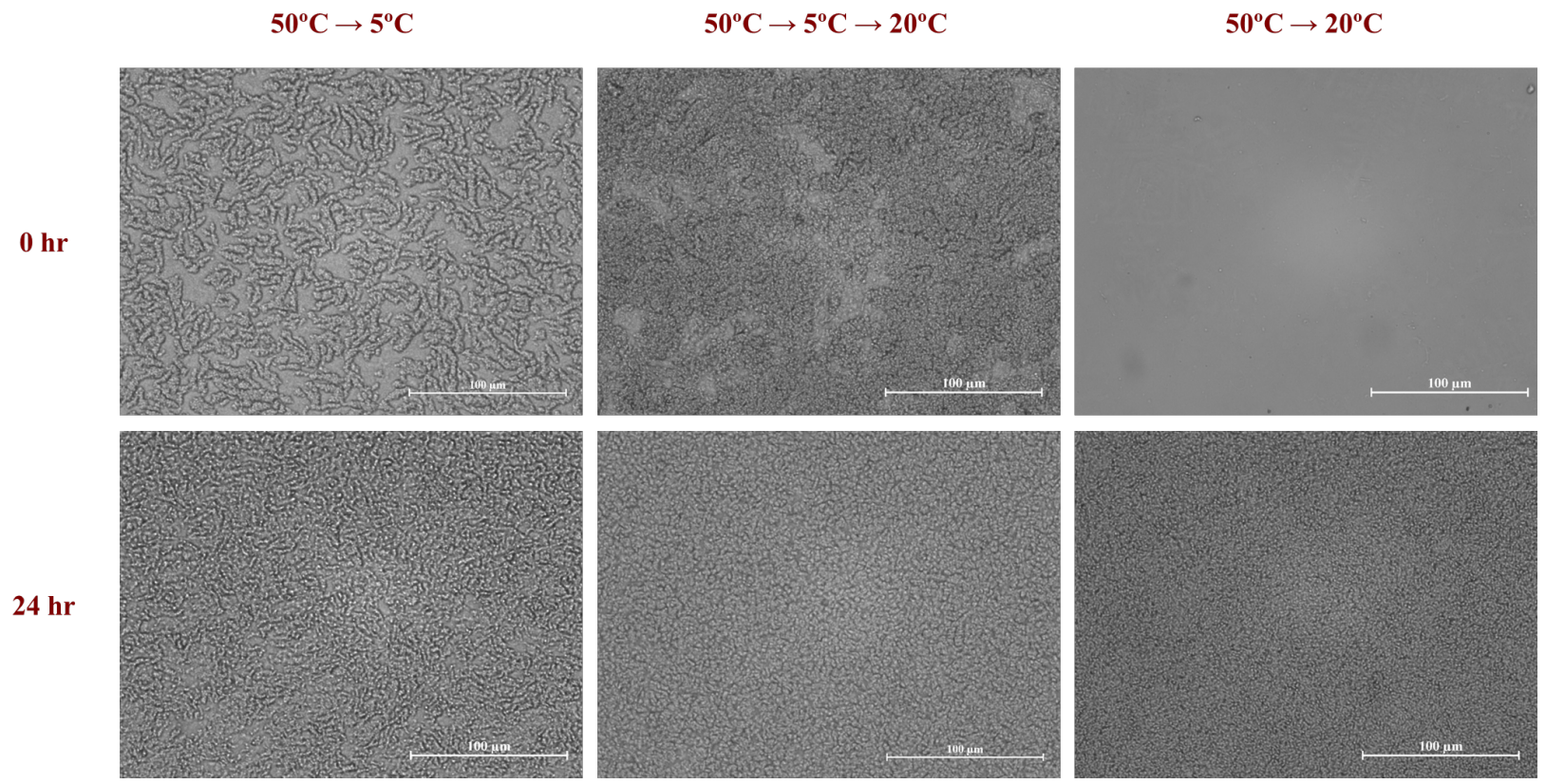

(a) 
$50^{\circ} \mathrm{C} \rightarrow 5^{\circ} \mathrm{C} \rightarrow 25^{\circ} \mathrm{C}$

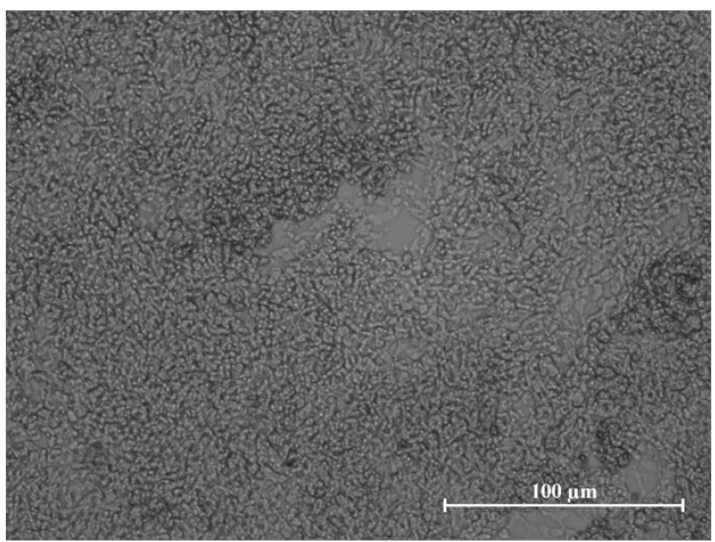

o hr

$24 \mathrm{hr}$

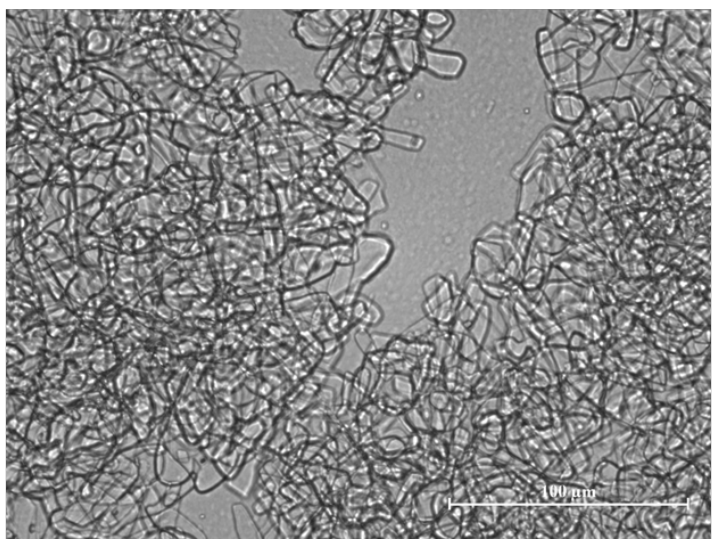

$50^{\circ} \mathrm{C} \rightarrow 25^{\circ} \mathrm{C}$
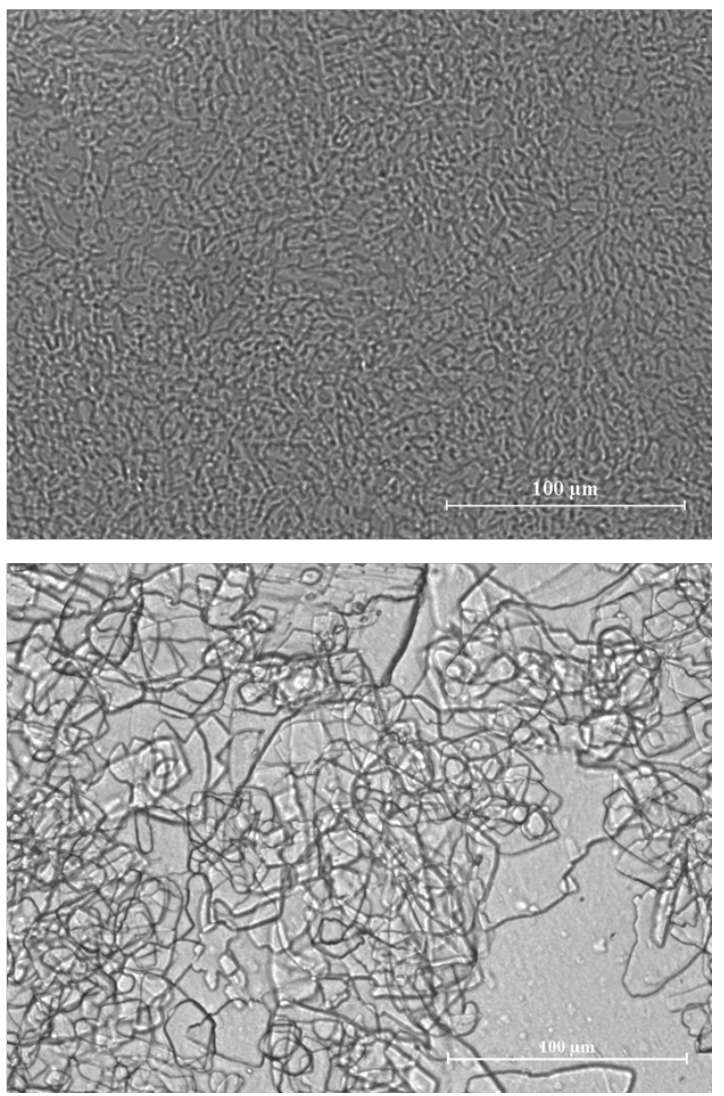

(b) 

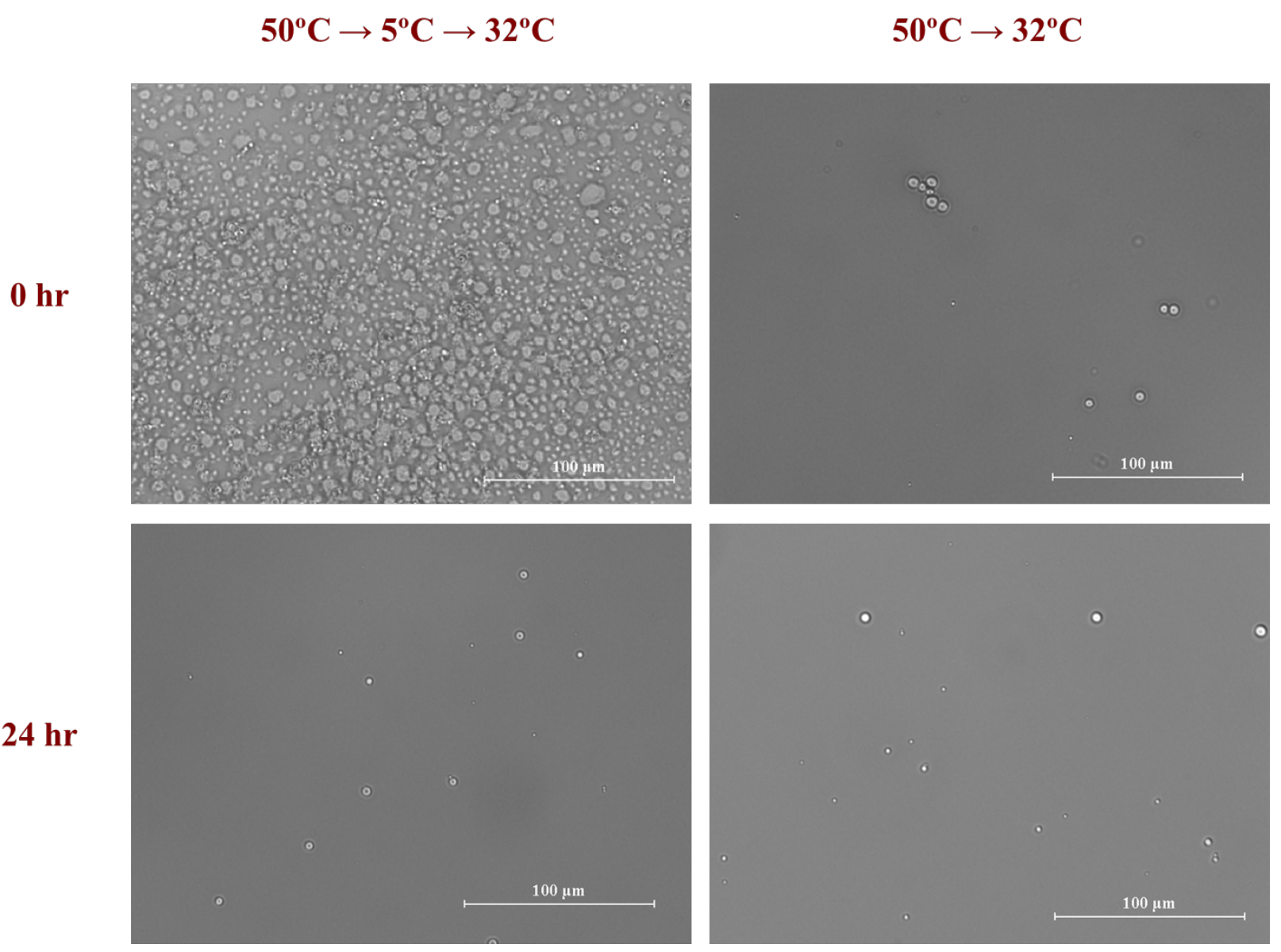

(c)

Figure 5: Optical microscopy images of surfactant/oil/water mixtures with different thermal histories taken at 0 hours or after 24 hours storage. The scale bars are $100 \mu \mathrm{m}$ in length. 


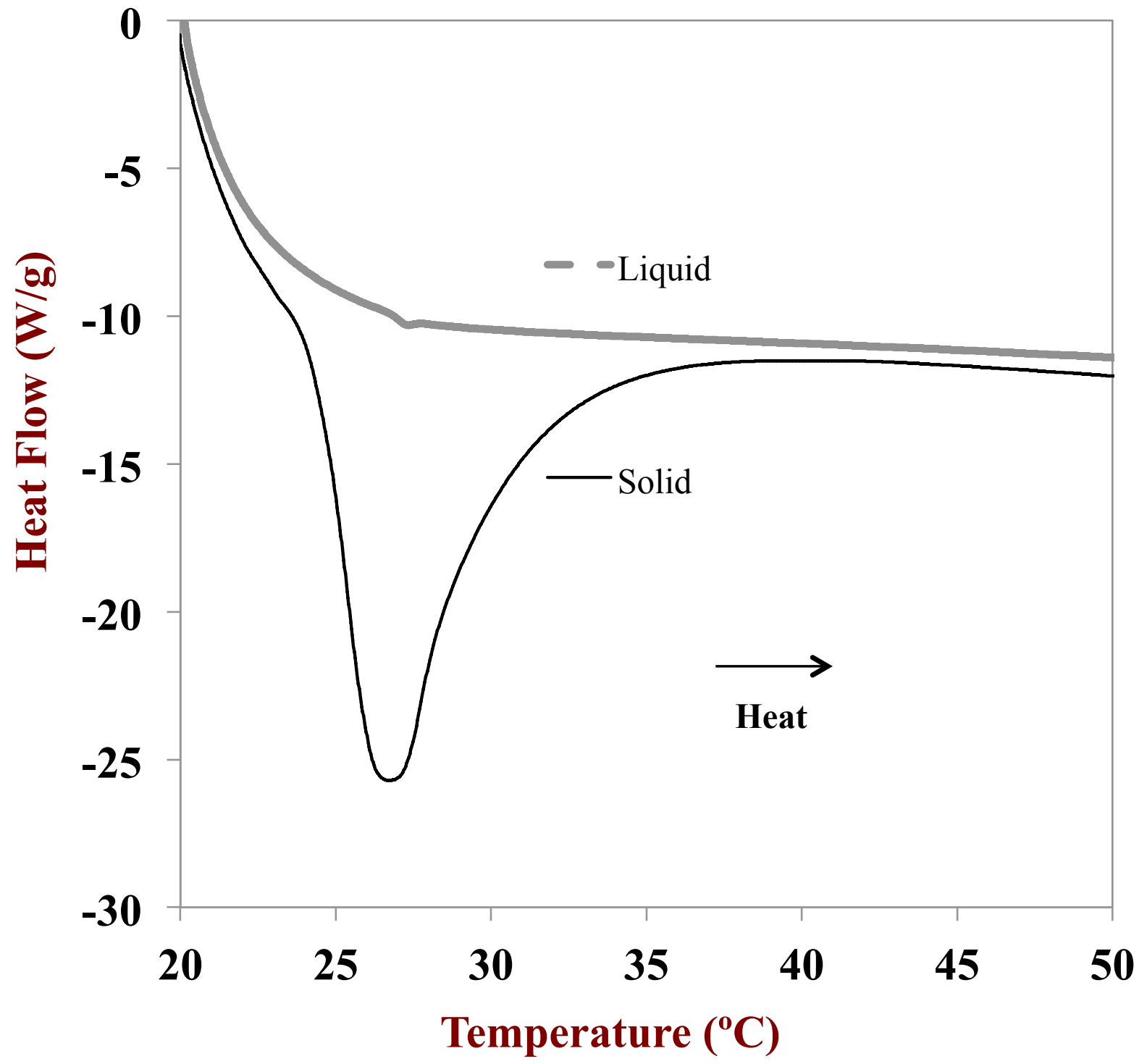

Figure 6: DSC profiles of lipid nanoparticle suspensions during heating at a controlled rate of 20 ${ }^{\circ} \mathrm{C} \mathrm{min}^{-1}$. SLNs were prepared by cooling from 50 to $5^{\circ} \mathrm{C}$ and then heating to $20^{\circ} \mathrm{C}$ (solid), while LLNs were prepared by cooling directly from 50 to $20^{\circ} \mathrm{C}$ (liquid). 


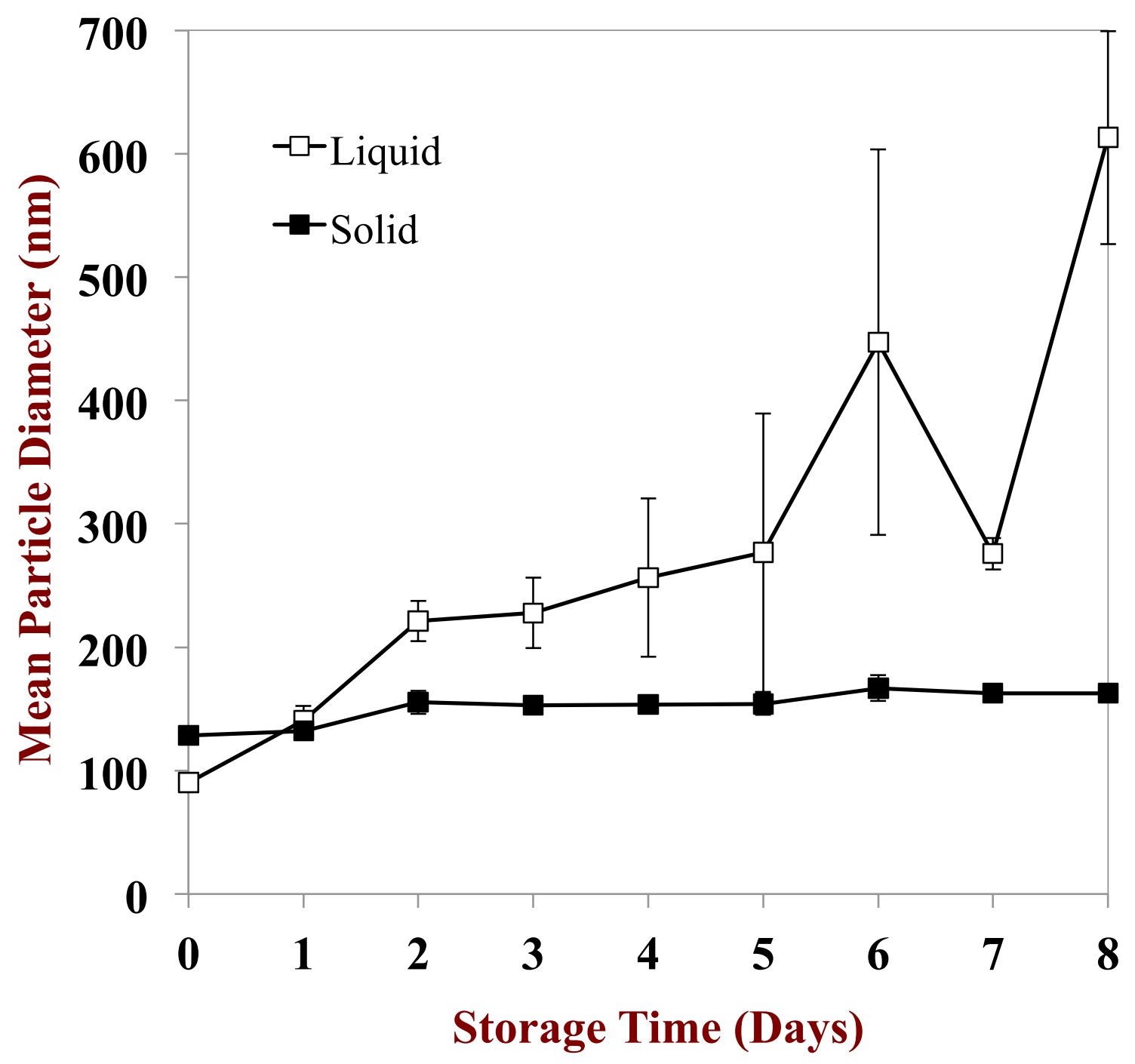

Figure 7: Changes in mean particle diameter of SLNs and LLNs during storage at $20^{\circ} \mathrm{C}$. 


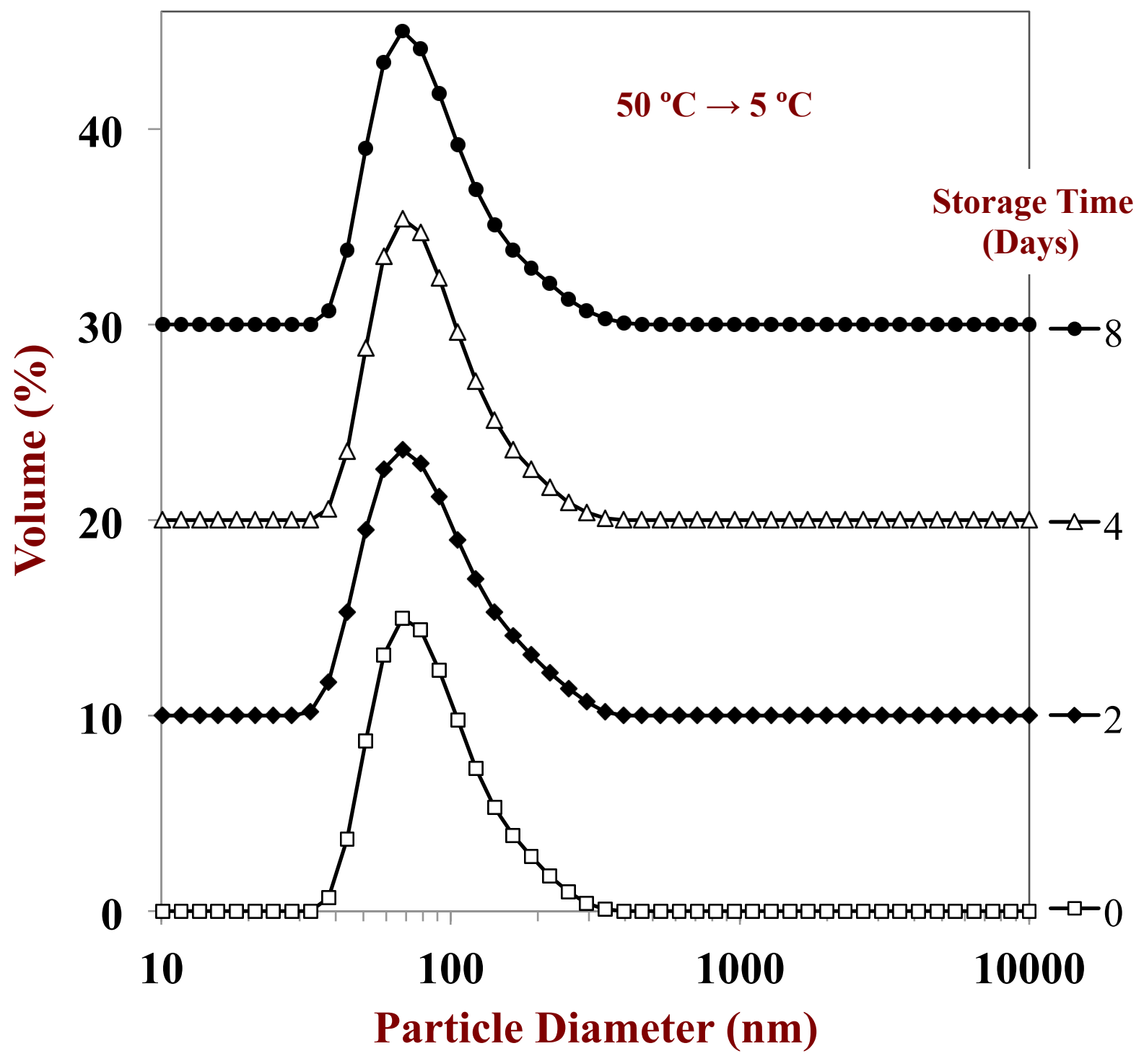




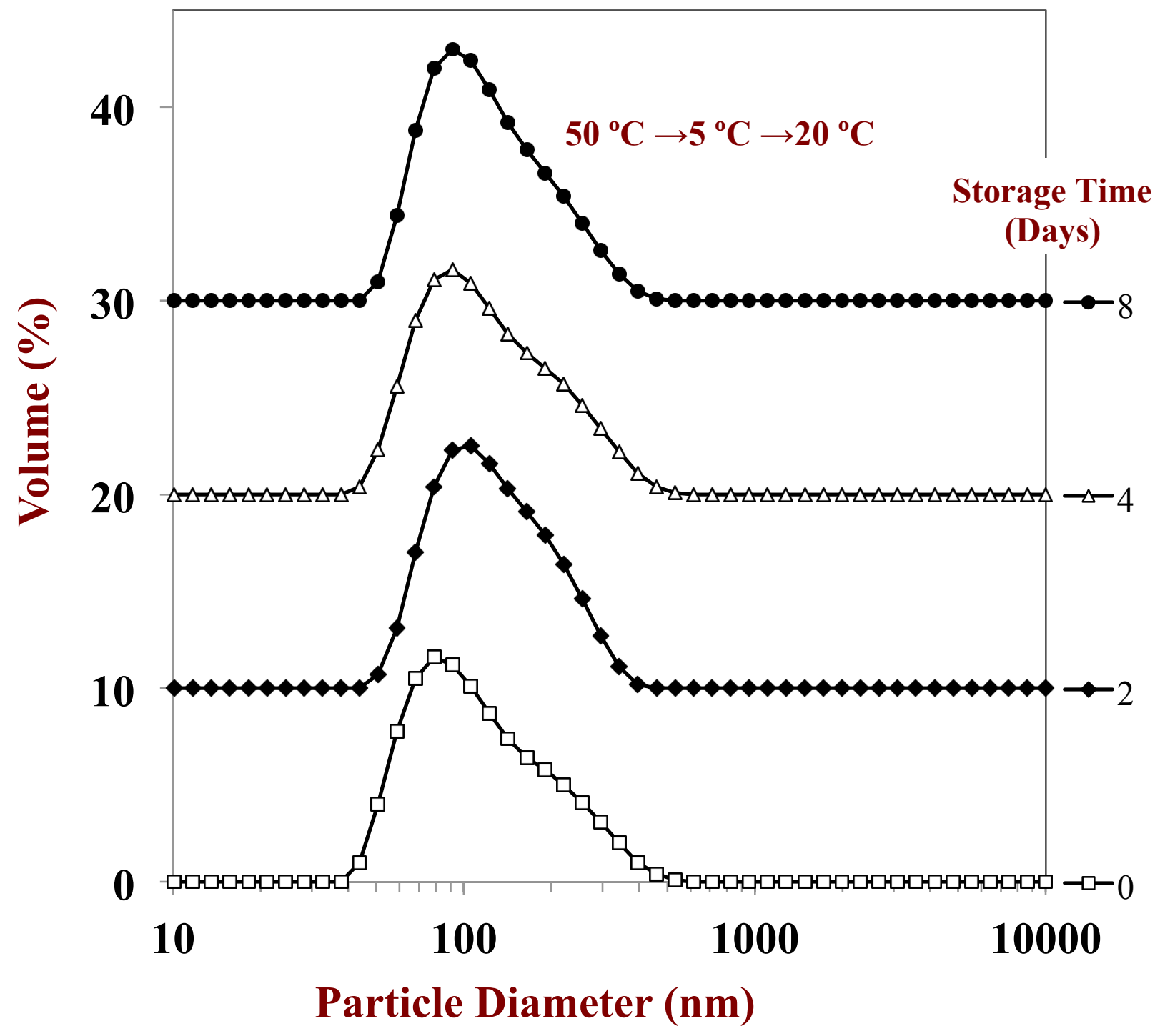




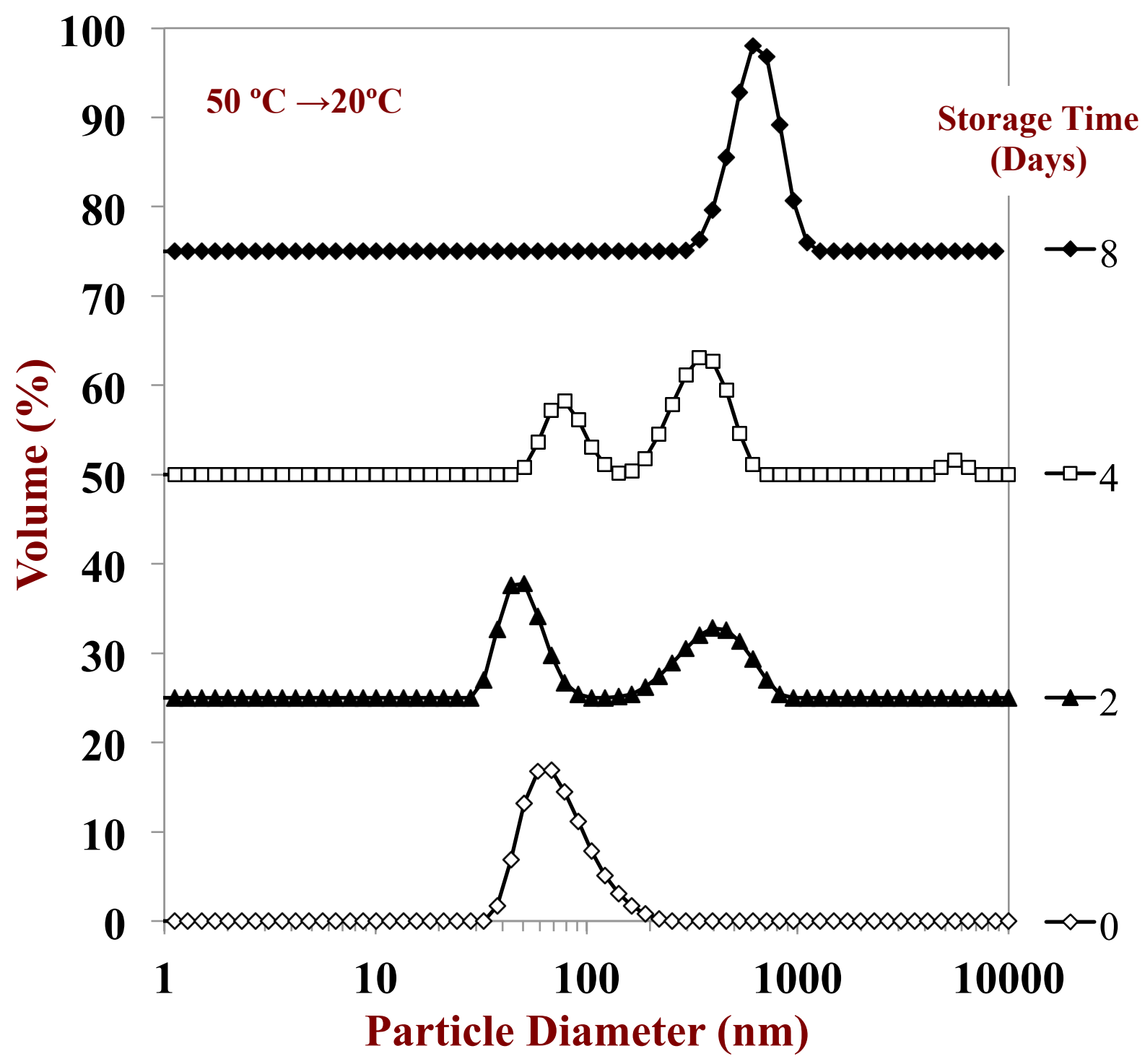

Figure 8: Changes in the particle size distribution of SLNs or LLNs during storage: SLNs were prepared by cooling from 50 to $5^{\circ} \mathrm{C}$ (a), and then heating to $20^{\circ} \mathrm{C}(\mathrm{b})$, while LLNs were prepared by cooling directly from 50 to $20^{\circ} \mathrm{C}$ (c). 